\title{
Amor e relacionamentos amorosos no olhar da psicologia ${ }^{1}$
}

\author{
Love and loving relationships in the eyes of psychology \\ Isabella de Carvalho Cerqueira ${ }^{\dagger}$, Fátima Niemeyer da Rocha $^{{ }^{*}}$
}

Como citar esse artigo. Cerqueira, IC; Da Rocha, FN. Amor e relacionamentos amorosos no olhar da psicologia. Revista Mosaico. 2018 Jul./Dez.; 09 (2): 10-17.

\begin{abstract}
Resumo
O estudo objetivou discutir a experiência do amor em seus diferentes âmbitos, no sentido de melhor compreender os motivos que movem o ser humano na busca pelo relacionamento amoroso. Apresenta um breve relato das concepções do amor no Ocidente, demonstrando o quanto essas concepções mudaram no decorrer da história do mundo e, a partir de tais concepções, desenvolve uma breve análise sobre o motivo pelo qual as pessoas se engajam e investem em relações amorosas. Discorre a respeito das teorias psicológicas sobre o amor, mais precisamente a Teoria do Apego de John Bowlby e a Teoria Triangular do Amor de Robert Sternberg, examinando a crença de que o insucesso do relacionamento amoroso pode ocorrer pela decepção do indivíduo com aquilo que buscou, a partir do que entendeu como sendo o seu ideal de amor. E discute a ideia de construção da conjugalidade baseada no autoconhecimento do indivíduo, dado que, como consequência, a busca pelo relacionamento amoroso se entrelaça a todo momento com sua concepção de si mesmo. Foi possível perceber que o campo sentimental se apresenta de forma distinta para cada indivíduo envolvido em um relacionamento amoroso, tornando a experiência do amor única para cada um.

Palavras-Chave: Amor; Relacionamentos Amorosos; Psicologia.
\end{abstract}

\begin{abstract}
The study aimed to discuss the experience of love in its different spheres, in order to better understand the motives that move the human being in the quest for love relationship. It presents a brief account of the conceptions of love in the West, demonstrating how these conceptions have changed throughout the history of the world and, from such conceptions, develops a brief analysis of why people engage and invest in love relationships. He discusses psychological theories about love, more precisely John Bowlby's Theory of Attachment and Robert Sternberg's Triangular Love Theory, examining the belief that the failure of the love relationship can occur through the individual's disappointment with what he sought, from what he understood to be his ideal of love. And he discusses the idea of constructing conjugality based on the self-knowledge of the individual, since, as a consequence, the search for the loving relationship is intertwined at all times with his conception of himself. It was possible to perceive that the sentimental field presents itself in a different way for each individual involved in a loving relationship, making the experience of love unique for each one. Keywords: Love; Loving Relationships; Psychology.
\end{abstract}

\section{Introdução}

Discorrer sobre o amor e os relacionamentos amorosos traz à tona as questões que envolvem sua historicidade, os motivos que impulsionam o indivíduo na sua busca e a influência da concepção de si mesmo sobre tais relacionamentos e a conjugalidade. Trata-se de um tema complexo, ao mesmo tempo antigo e atual, enfocado, principalmente, a partir das abordagens de John Bowlby (Teoria do Apego), de Robert J. Sternberg (Teoria Triangular do Amor) e de Zigmund Bauman (Teoria da Modernidade Líquida).

O estudo de revisão de literatura teve o objetivo de abordar a experiência do amor em seus diferentes âmbitos, assim como as concepções do amor no Ocidente e as teorias psicológicas sobre o amor, com o propósito de melhor compreender os motivos que movem a busca pelo relacionamento amoroso. Abordou, ainda, algumas outras questões relativas ao tema, como a conjugalidade e de que forma as concepções que o indivíduo tem de si mesmo podem afetar a maneira com a qual conduz seu relacionamento.

\section{As concepções do Amor}

Ao descrever brevemente as concepções do amor através da história do amor no Ocidente "[...] é possível perceber as diferentes configurações de amor produzidas pelos clássicos, pelo cristianismo, pela sociedade de cortesia (séc. XII), pelo amor-paixão romântico (XVIIIXIX) e pela contemporaneidade". (MAHEIRIE et al.,

\footnotetext{
Afiliação dos autores:

$\uparrow$ Graduada em Psicologia, no Curso de Psicologia da Universidade de Vassouras, Vassouras, RJ, Brasil

* Doutora em Psicologia, Professora Titular do Curso de Psicologia da Universidade de Vassouras, Vassouras, RJ, Brasil

*Email para correspondência: fatimaniemeyer@hotmail.com
}

${ }^{1}$ O Presente texto tem como base um Trabalho de Conclusão de Curso apresentado ao Curso de Psicologia da Universidade de Vassouras 
2009, p. 396).

Platão, na Antiguidade, utiliza os mitos para ilustrar suas definições. Sua obra "O Banquete" narra que o amor nasceu do Recurso e da Pobreza. Isso significa que o amor: "Primeiramente ele é sempre pobre e está longe de ser delicado e belo, como a maioria imagina, mas é duro, seco, descalço e sem lar, sempre por terra e sem forro, deitando-se ao desabrigo [...] ele é, porém, insidioso com que é belo e bom, e corajoso, decidido e enérgico". (PLATÃO 1973 apud SAVIAN FILHO, 2016, p. 144). Platão tenta demonstrar que o amor não é algo simples, mas está carregado de certa carência; e o que impulsiona a busca do amor é a possível promessa de que a necessidade seja suprida; quando encontrado, o indivíduo se sente completo. Para Savian Filho (2016, p. 144), "diante de alguém que representa a possibilidade de preenchimento da carência, a pessoa amante fica fascinada e se deixa tomar pelo amor".

Ainda no "Banquete", Platão descreve que, diante da intemperança dos seres humanos, Zeus criou uma estratégia de refrear tal comportamento fazendo com que fossem divididos em duas partes. Novamente, a questão de carência e da supressão da falta é abordada, visto que, no sentido dos amantes, na visão de Zeus, sua divisão em dois os colocaria diante da necessidade da busca e do encontro de sua metade perfeita. No entanto, para Platão, “o amor não é uma simples 'colagem' de duas metades e nem uma fusão entre elas" (SAVIAN FILHO, 2016, p. 146). Se assim fosse, isso significa que a busca pela completude e satisfação de seus desejos estaria findada. Mas, pelo contrário, sabe-se que mesmo quando se encontra a pessoa tida como ideal não é isso que acontece, porque ainda existem outras necessidades a serem supridas. Savian Filho (2016, p.146) complementa que "os deuses cortaram tão bem as metades humanas que elas se tornaram semicírculos: pelo amor, elas podem formar novamente um círculo, mas continuam sempre independentes; nunca mais formarão um círculo unitário". A partir do momento em que se tornam metades, os indivíduos passam a ter desejos e vontades próprias; com isso, encontrar sua metade perfeita torna-se um complemento ou não daquilo que buscam além do amor - e pode-se ser feliz com alguém que não seja exatamente como você.

Outro ponto abordado por Platão é a relação entre a beleza e o amor. Para ele beleza é "o que atrai o ser humano em tudo que lhe oferece satisfação" (SAVIAN FILHO, 2016, p. 147). A beleza à qual Platão se refere não deve ser confundida com padrão de beleza, embora possa ter alguma semelhança com esse conceito. Savian Filho (2016, p. 148) afirma que "dessa perspectiva, a beleza, segundo Platão, liga-se ao encanto produzido pelo modo de ser das pessoas, coisas e ações. Esse é o modo que atrai e satisfaz os amantes". Pode se dizer que Platão se refere à beleza interior e o que essa beleza causa nas pessoas que expressam esse sentimento.
Outra concepção de amor, é a do amor sagrado, abordada por filósofos que, em sua maioria, não concordavam com a ideia de Platão de que o amor era algo que nos faria buscar o melhor, pois, para eles, o amor seria algo muito maior e mais altruísta do que buscar a completude em outra pessoa. Nesse ponto de vista, Tomás de Aquino, na Idade Média, via a criação do mundo como um ato de amor de seu criador para com seus filhos, sem nenhuma intenção de troca ou necessidade de outra pessoa para se sentir amado; acreditava no amor no seu sentido mais total, o amor simplesmente dado, sem esperar por recompensa.

Essa abordagem de amor sagrado engloba também o conceito de amizade; a amizade entre Deus e os seres humanos se mantém mesmo que haja erros ou falta de fé; é um amor inabalável; ter o amor de Deus já seria o suficiente para alcançar o propósito do amor, sem precisar de um amor romântico, no sentido de amante. "Entendidos em sua imperfeição, os amigos (e todos os seres humanos) podem ser amados pelo simples poder de amar." (SAVIAN FILHO, 2016, p. 169). "Em comparação com o mundo antigo, a amizade ou o amor de amigo é transfigurada, pois se revela uma forma de amar os amigos também com um amor total, sem recompensa para além do próprio amor ou da satisfação obtida com o simples ato de amar" (SAVIAN FILHO, 2016, p. 168). O amor sagrado se revela como o ato de amar sem esperar nada em troca e sem julgar aquele que se ama; é o ato de amar com toda a pureza que esse ato possa significar.

Ainda na Idade Média, encontramos o amor cortês, ilustrado na história de Tristão e Isolda. Tristão era um jovem que prometeu ao seu tio buscar a filha do rei da Irlanda para que ele a tomasse como sua esposa. No caminho de volta para casa, Tristão e Isolda tomaram um poção que a mãe da moça havia feito para que ela se apaixonasse pelo tio de Tristão. Após tomarem a poção ambos se apaixonaram perdidamente, mas o jovem manteve a promessa de levar a moça para casar-se com o tio. Com o passar dos anos, Tristão se casou com uma outra moça também chamada Isolda e com ela foi morar longe de seu tio e de Isolda, a Loira. Após alguns anos ele fica muito ferido e pede para que um amigo busque Isolda, seu antigo amor, pedindo que a vela do navio que a trouxesse fosse branca, caso ela aceitasse ir até ele; caso contrário, as velas do navio deveriam ser pretas. Isolda, a esposa de Tristão, ao ver o navio se aproximar disse para o marido que as velas eram pretas, mas na verdade eram brancas, fazendo com que Tristão se suicidasse. Isolda, ao chegar e vê-lo morto, desmaia e bate a cabeça, morrendo também. Ao serem enterrados juntos, duas plantas nascem dos túmulos e se fundem, tornando-se uma só. (SAVIAN FILHO, 2016)

O amor cortês, como representado no romance de Tristão e Isolda, é carregado de dramaticidade e tragédia. Segundo Savian Filho (2016, p. 183), "Pode-se resumir 
em dois pontos o que Tristão e Isolda ensinam: o amor é irresistível (ele nasce nos seres humanos, sem que eles o forcem) e o amor pode produzir ordem e desordem na vida pessoal e social". O amor de Tristão e Isolda não foi premeditado, nem puderam controlar o sentimento que nutririam um pelo outro e, consequentemente, não sabiam que esse sentimento traria a tragédia para suas vidas e de todos os outros envolvidos nesse acontecimento.

Para os trovadores que contavam esse tipo de romance a intenção era conquistar as mulheres, mostrando a delicadeza do amor através dessas histórias - era um método de sedução. "Seja como for, o jogo de sedução passa a ser concebido como atividade masculina como exaltação da mulher amada." (SAVIAN FILHO, 2016, p. 185). A idealização do ser amado apresentada nesses romances, além de aguçar a imaginação de homens e mulheres da época, também despertava uma insatisfação por saber que a realidade não era compatível com o que se ouvia, era uma forma de satisfazer-se com uma fantasia.

Nos séculos XIX e XX, o conceito de amor toma uma nova forma, principalmente a partir do movimento feminista, atuante na época, como em Judith Butler e Simone de Beauvoir. Savian Filho (2016, p. 196) argumenta que "Simone de Beauvior, por exemplo, denunciava que a história filosófica do amor era uma história escrita por homens, sem levar em conta o fato de que a palavra amor não ter o mesmo significado para homens e mulheres".

A ideia de amor no contemporâneo, trazida por Beauvoir, critica o modelo de amor cortês, pois não passaria de uma fantasia para que os homens conquistassem as mulheres com suas poesias, com base em um sentimento que, talvez, muitos deles nem sentissem de verdade. Outro ponto interessante é que as poesias cantadas pelos trovadores falavam da mulher ideal, o que, de certa forma, fez com que as mulheres daquela época, e das épocas posteriores, buscassem um padrão de feminilidade a partir daquilo que era dito por eles: "o amor não passaria de uma invenção cultural e machista." Beauvior denuncia que as vontades dos homens deveriam prevalecer, fazendo com que as mulheres buscassem formas de acompanhar padrões de beleza muito parecidos com aqueles fantasiados pelos trovadores do amor cortês. (SAVIAN FILHO, 2016, p. 196)

Beauvoir (1990), por sua vez, destaca a negação das contingências e da existência concreta do outro, e a exaltação de aspectos deterministas nessas experiências amorosas, o que configura o amor como um destino na vida dos sujeitos, em especial para as mulheres, portanto, comprometendo assim, igualmente, uma experiência amorosa livre. (MAHEIRIE et al., 2009, p.397).

Judith Butler apresenta um pensamento diferente de Simone de Beauvoir, ao afirmar que "o amor não é algo que se sente, e sim uma relação que se constrói por trocas entre pessoas". (SAVIAN FILHO, 2016, p. 196) Butler quer mostrar que não é possível se descobrir o amor sem o convívio, sem nenhuma atividade em comum, sem contato; o amor é construído dia a dia e em conjunto. Ela enxerga o amor como uma relação que deve ser construída pouco a pouco sem que o sentimento seja o foco principal; o amor surgiria, então, a partir da relação e não como o seu centro.

Uma crítica que tanto Simone de Beauvoir como Judith Butler fazem em relação ao amor na contemporaneidade, é a de que "se o amor é algo que não pode ser avaliado objetivamente, nada justificaria tomálo como orientação da vida moral ou ética". (SAVIAN FILHO, 2016, p. 196) Ou seja, para elas o amor não deve ser o que dirige a vida do indivíduo, não deve ser visto como uma lei universal que deve ser seguida moral e eticamente. Mas também não descartam a existência dele. O que quer dizer que se deve enxergar o que está para além do amor.

Diante das diferentes concepções do amor, deve-se ressaltar que elas mudam de acordo com o momento social, histórico e cultural em que ocorrem; as mudanças surgem com as transformações que ocorrem nas visões de mundo: "O amor seria uma experiência emocional que muda de acordo com o ambiente social." (SHIRAMIZU e LOPES, 2013, p. 57).

Nesse sentido, é possível o amor (um sentimento) sem que a paixão e a atração (emoções) estejam presentes o tempo todo entre os parceiros, porque o amor não está alicerçado em prazeres imediatos, mas sim numa temporalidade histórica sintetizada por um eu, que, por isso mesmo, envolve toda a constituição do sujeito. (MAHEIRIE et al., 2009, p. 401).

A esse respeito Shiramizu e Lopes (2013, p. 57) aduzem que "os estudos sistemáticos iniciais sobre amor sempre estiveram no âmbito da perspectiva social, notadamente no campo da psicologia social e da personalidade, e uma das grandes dificuldades era de como defini-lo." Nessa perspectiva, discorre sobre os vários tipos de amor, cada um com um estilo diferente, podendo ser divididos em grupos, como:

Eros (caracterizado pela busca da pessoa amada, cuja imagem já está representada na mente do amante), Ludus (estilo de amor em que o amante "coleciona" experiências, as quais são lembradas com prazer) e Storge (o amor como amizade, onde os parceiros acostumam-se um com o outro); e um grupo secundário: Mania (caracterizado pelo ciúme, pela obsessão e maior intensidade emocional), Agape (estilo sacrificante, no qual o bem-estar da pessoa amada é colocado acima de tudo) e Pragma (um estilo de amor racional, em que as decisões são tomadas mais pela razão do que pela emoção) (SHIRAMIZU e LOPES, 2013, p. 58).

Reforçando as ideias de que não existe uma concepção única ou ideal de amor, seus estilos mudam 
concepção única ou ideal de amor, seus estilos mudam com o tempo e se diferenciam de indivíduo para indivíduo, Maheirie et al. (2009, p. 402) apontam para o fato de que:

Desse modo o amor, como uma das possíveis relações que os sujeitos estabelecem entre si, extravasa as individualidades para se inserir na arena social, política, ideológica de uma época histórica, sendo, justamente, a partir dessa totalidade de olhares que adquire função, significação e sentido.

Podemos dizer, então, que no decorrer da história as concepções do amor demonstram suas várias faces e formas; o conceito de amor é diferente para cada indivíduo, é subjetivo e imensurável e deve ser entendido tendo em mente o espaço histórico e temporal de cada sujeito que vivencia esse sentimento.

\section{A Busca por relacionamentos amorosos}

A demanda de relacionamentos amorosos ao longo da vida de uma pessoa pode ser comparada a busca pela felicidade, para muitos compreendida como o único fator que traria completude ao indivíduo. Estar com uma pessoa em uma relação de amor pode instituir uma espécie de status mais alto para o indivíduo, em comparação com aqueles que não estão nessa situação. "Nota-se que as pessoas estão constantemente buscando fazer ligações em suas vidas para encontrar alguém para ficar, namorar, casar ou formar uma família. Há evidências de que há um desejo natural na busca pelo outro. E quando há o encontro, simplesmente há!" (KUHN, 2013, p. 4)

Porém, estabelecer um relacionamento pode ser uma necessidade para alguns e não para outros, pois cada um faz suas próprias escolhas quanto a sua vida amorosa, e engatar um relacionamento pode fazer parte dos seus planos ou não. "De fato, é possível, que alguém se apaixone mais de uma vez, e algumas pessoas se gabam - ou se queixam - de que apaixonar-se e "desapaixonar-se" é algo que lhes acontece (assim como outras pessoas que vêm a conhecer nesse processo) de modo muito fácil”. (BAUMAN, 2004. p. 18).

A visão que cada indivíduo tem de suas necessidades amorosas é subjetiva e cada um vai se adaptar ao que cabe à sua necessidade, de acordo com o meio em que foi criado, a partir das histórias que ouviu quando era criança e também pelo que lhe agrada no outro. Não cabe julgar a forma de amor que desperta o interesse do outro. Além disso, várias questões entram em cena quando o assunto é o amor. Uma delas é o motivo pelo qual busca-se um relacionamento amoroso. Para Bauman (2004, p. 21) "Amar significa abrirse ao destino, a mais sublime de todas as condições humanas."

Ao levar em consideração o mundo em que se vive hoje, com todas as suas tecnologias e uma gama de redes sociais que modernizam, aceleram e promovem cada vez mais rápido os relacionamentos amorosos, Kuhn (2013) descreve três fases principais de um relacionamento adulto: o paraíso, o purgatório e o inferno. Sobre a fase de paraíso dos relacionamentos, Kuhn (2013, p. 2) esclarece:

Sites de relacionamentos, mensagens de celulares, e-mails, ligações, círculos de amizades e até mesmo o meio profissional tornaram-se acessíveis e susceptíveis a alterações pelo outro, perde-se a individualidade. No paraíso a perda da individualidade é encarada como uma total entrega ao outro, a passagem do "meu" para o "nosso" em quase todos os setores da vida dos amantes é maravilhosa, suave e imperceptível.

Quanto à perda da individualidade enfatizada por Kuhn, podemos relacioná-la a concepção de Platão apresentada no "Banquete", em que a busca do amor é guiada pela promessa de suprir uma necessidade, uma falta, e ao encontrar o amor nos entregamos, como diz Kuhn, perdemos a individualidade, numa total entrega ao outro. E enquanto Platão afirma que o indivíduo só encontraria completude se encontrasse sua outra metade, Kuhn sugere que a passagem do "meu" para o "nosso" se dá no mesmo sentido, de entregar-se e completar-se.

Por outro lado, o purgatório sugerido por Kuhn (2013) começa exatamente nesse ponto, quando há a perda da privacidade dentro do mundo virtual, muito presente no dia a dia de todas as pessoas. "Adiferenciação é o que marca o purgatório. O "eu" passa a reivindicar seu espaço perdido, a individualidade outrora perdida. $\mathrm{O}$ desejo de privacidade em senhas, e-mails, mensagens etc., vai tornando-se mais constante." (KUHN, 2013, p. 3). E a busca por esse espaço sem a pessoa amada não significa falta de amor, mas sugere que para essa relação manter-se sólida é necessário um pouco de espaço para o indivíduo exercitar o que é ser ele mesmo, sem ter o parceiro ao lado.

A fase do purgatório de Kuhn pode ser relacionada ao amor na contemporaneidade ilustrado nas ideias de Butler; esta crê que o amor não se resume ao que se sente, porque é algo que se constrói dia após dia. Mas para essa construção se consolidar é preciso enfrentar o que é sugerido por Kuhn na ideia de purgatório:

Devido ao intenso sentimento de amor e entrega ao outro, nessa fase deflagra-se de forma mais constante os conflitos. Devido à ambiguidade de sentimentos, o querer o outro e ao mesmo tempo desejar a própria individualidade, cria-se constantes conflitos em que ora luta-se pela relação, ora luta-se pela própria individualidade. (KUHN, 2013, p. 3)

É exatamente na construção do relacionamento, conforme Kuhn (2013), que nasce o amor no qual os indivíduos vão se conhecendo - e construindo sua relação. Nesse contexto, a fase do purgatório não deve ser compreendida necessariamente como algo ruim, 
mas uma fase em que, após a euforia do paraíso, se começa a enxergar o outro real. $\mathrm{O}$ amor, nessa fase, não é o centro da relação, mas sim o que parte dele. Os conflitos e o "discutir a relação" surgem como forma de propor o que é melhor para arquitetar o relacionamento, onde cada indivíduo deveria se reconhecer dentro do relacionamento, o que é crucial para se conhecer os rumos da relação.

E a fase do inferno seria a última tentativa de fazer o relacionamento funcionar, podendo haver êxito ou não nesse processo. "O fogo ardente da paixão é substituído pelo fogo das brigas, das traições, do controle, da possessão, da dependência, do apego, da simbiose quase patológica a que a relação foi elevada”. (KUHN, 2013. p. 4) Nessa fase, o amor é questionado, pois a paixão que estava presente nas fases anteriores se extinguiu. É o momento em que se busca respostas para a pergunta: Por que o amor acabou? Dentre as possibilidades apresentadas por Kuhn (2013, p. 4) estão: "terapia de casal, apelo à religião, idas ao psiquiatra, promessas de mudança, e medidas menos conservadoras [...] Cada casal arranja um jeito ou se desarranja nessa fase."

$\mathrm{Na}$ visão de Bauman (2004), que se pode aproximar, de certa forma, tanto da crítica a ideia do amor cortês como da fase denominada inferno por Kuhn,

A oferta de aprender a arte de amar é a oferta (falsa, enganosa, mas que se deseja ardentemente que seja verdadeira) de construir a "experiência amorosa" à semelhança de outras mercadorias, que fascinam e seduzem, exibindo todas essas características que prometem desejo sem ansiedade, esforço sem suor e resultados sem esforço. (BAUMAN, 2004, p. 22)

Bauman não descarta a possibilidade da existência do amor, mas ao compará-lo com mercadorias que apenas fascinam, salienta que estar em um relacionamento aponta para uma questão, muito mais forte, de ter um status social, do que uma questão amorosa em si. Ao assumir um relacionamento na intenção de obter apenas status, o amor torna-se "uma hipoteca baseada num futuro incerto e inescrutável" (BAUMAN, 2004, p. 23). Isso torna a fase do inferno de Kuhn real e constante, pois muitos relacionamentos acabam pelo fato dos casais não terem ideia de como vencer essa fase e por não compreenderem que o relacionamento é construído por momentos bons e ruins.

O conceito de amor líquido, de Bauman (2004), que traz para a discussão a fragilidade dos laços humanos, faz uma crítica ao modelo de amor que vivenciamos na contemporaneidade. $\mathrm{O}$ amor tornou-se tão banalizado que pode ser comparado a produtos de consumo, algo que pode ser comprado, de fácil manipulação e que, quando não satisfaz mais o comprador, pode ser trocado por outro melhor e mais novo. "É como num shopping: os consumidores não compram para satisfazer um desejo, compram por impulso." (p. 26). O que move a vontade de apaixonar-se e desapaixonar-se é o desejo do consumo, aqui caracterizado pela variedade de relações amorosas.

A súbita abundância e a evidente disponibilidade das "experiências amorosas" podem alimentar (e de fato alimentam) a convicção de que amar (apaixonar-se, instigar o amor) é uma habilidade que se pode adquirir, e que o domínio dessa habilidade aumenta com a prática e a assiduidade do exercício. (BAUMAN, 2004, p. 19)

Bauman (2004) menciona as relações de bolso que são curtas e agradáveis, que se tornam cada vez mais comuns, pois se encaixam na correria da vida atual, mas que são, ao mesmo tempo, frágeis e carentes de cuidado; mas o foco é que você esteja satisfeito e no controle. "A conveniência é a única coisa que conta, e isso é algo para uma cabeça fria, não para um coração quente (muito menos superaquecido)" (p. 37).

Pode-se entender melhor do que se trata o conceito de amor líquido de Bauman, quando consideramos o conceito de hipermodernidade, de Lipovetsky, para definir o momento em que nos encontramos. Conforme Braga (2010, p. 10), a hipermodernidade é "entendida como a modernidade elevada a sua máxima potência, alguns aspectos tomam força e se sobressaem com mais nitidez: é o tempo do hiperindivíduo, do hiperconsumo e do hipernarcisismo". Sobre Lipovetsky e a hipermodernidade, Braga (2010) reflete que: "Segundo o autor, a passagem do mundo industrial (modernidade) para a globalização (pós-modernidade) provocou mudanças significativas tanto no âmbito coletivo quanto individual, culminando em uma espécie de desorientação, fruto da horizontalização dos laços sociais". (BRAGA, 2010, p. 50)

Dizer que os laços sociais estão estremecidos a partir da nova dinâmica vivenciada na hipermodernidade, se relaciona com o que Bauman (2004) apresenta como fragilidade dos laços humanos, que se encontram nos relacionamentos de bolso, carregados de promessas quanto ao que podem vir a ser ou significar. Mas, na realidade, o indivíduo envolvido nesse tipo de relação sabe que ela é volátil e que não dá garantias - e é aí que está a sua fragilidade.

Então, por que razão os seres humanos buscam o amor? Bauman (2004) indica algumas razões; entre elas, o fato de apaixonar-se, percebido como algo tentador, tendo em vista o fascínio da própria procura do amor. $\mathrm{O}$ que desperta o movimento da busca é querer aquilo que parece impossível de conseguir e conquistar: é como "uma rosa sem espinhos, nunca está muito longe, e é sempre difícil de resistir." (p. 23). Outra razão sugerida por Bauman (2004), se refere a segurança - estar em um relacionamento, na maioria das vezes, é visto como uma segurança de nunca se estar só, nutrindo a sensação de estar protegido e, de fato, seguro.

A proximidade da mão amiga quando você mais precisa dela, o socorro na aflição, a companhia na 
solidão. $\mathrm{O}$ apoio para sair de uma dificuldade, o consolo na derrota e o aplauso na vitória, e também a gratificação que nos toma imediatamente quando nos livramos de uma necessidade. (BAUMAN, 2004, p. 29).

Entretanto, Bauman também chama a atenção para o erro bastante comum de se buscar o amor simplesmente para fugir da solidão, principalmente diante da fragilidade desses laços, podendo ser um caminho doloroso e triste. "O que se propunha/ansiava/ esperava ser um abrigo (talvez o abrigo) contra a fragilidade revela-se sempre como uma estufa." (BAUMAN, 2004, p. 41).

Bauman alude, ainda, a outra razão para os seres humanos buscarem o amor: a vontade de construir algo junto com uma outra pessoa, vendo o relacionamento crescer e amadurecer, enquanto as pessoas envolvidas também amadurecem e crescem. Isso torna a busca interessante, diante da capacidade de construir algo único e belo, com alguém com quem se pode compartilhar sentimentos em comum. Ou seja, "não é ansiando por coisas prontas, completas e concluídas que o amor encontra o seu significado, mas no estímulo a participar da gênese dessas coisas" (BAUMAN, 2004, p. 21).

Podemos compreender, então, que o que move a busca por relacionamentos amorosos, e o que faz com que um relacionamento seja bem-sucedido, depende principalmente das escolhas das pessoas envolvidas.

\section{Teorias psicológicas sobre o amor}

A Teoria do Apego (TA), proposta por John Bowlby, organiza o comportamento de apego em termos de um sistema motivacional, na qual "o movimento individual de uma pessoa em direção a múltiplas outras converge para que a TA também seja considerada uma teoria relacional das interações sociopsicológica" (DALBEM e DELL'AGLIO, 2005, p. 3).

Pensando nos relacionamentos amorosos, "o papel do apego na vida dos seres humanos envolve o conhecimento de que uma figura de apego está disponível e oferece respostas, proporcionando um sentimento de segurança que é fortificador da relação" (CASSIDY, 1999 apud DALBEM e DELL'AGLIO, 2005 , p. 3). Seja a relação entre mãe e filho ou uma relação romântica, esta se estende para qualquer tipo de relação que o indivíduo venha a ter em sua vida.

Segundo Dalbem e Dell'Aglio (2005), um dos conceitos principais da Teoria do Apego é o do comportamento de apego, que se refere a "ações de uma pessoa para alcançar ou manter proximidade com outro indivíduo." (p. 4), encontrado na maioria dos relacionamentos amorosos. Por sua vez, Rodrigues e Chalhub $(2009$, p. 2) entendem que: "Um vínculo malformado com a principal figura de apego na infância traria transtornos nos relacionamentos na vida adulta, onde provavelmente o indivíduo com apego inseguro procurasse em seu respectivo parceiro o suprimento de um amor e afeto faltante". E Silva et al. (2013, p. 23) esclarecem que a justificativa para os insucessos dos relacionamentos amorosos é a malformação do vínculo criado na infância, em que se estabelece uma falta do apego seguro.

Reforçando o conceito de apego seguro, a Teoria do Apego aplicada a adultos utiliza três padrões de apego: apego seguro, apego ansioso/ambivalente e apego evitativo. (SHAVER et al., 1988 apud SILVA et al., 2013).

As pessoas com padrão de apego seguro descrevem seus relacionamentos como felizes, amigáveis e confiáveis e enfatizam a capacidade de aceitar e de apoiar o parceiro apesar das suas falhas. As pessoas com padrão evitativo apresentaram medo de intimidade, altos e baixos emocionais e ciúmes. Já as pessoas com o padrão de apego ansioso indicaram experiências que envolvem obsessão, desejo de reciprocidade e união, altos e baixos emocionais, grande atração sexual e ciúmes. (SILVA et al., 2013, p. 24).

Já a Teoria Triangular do Amor (TTA), proposta por Robert Sternberg, caracteriza esse sentimento a partir de "três componentes, intimidade, paixão e decisão/compromisso, que formam os vértices de um triângulo" (MÔNEGO e TEODORO, 2011, p. 97).

Intimidade (topo do vértice do triângulo). Este é um dos componentes dinâmicos mais valiosos. Referese àqueles sentimentos que promovem proximidade, vínculo e conexão nos relacionamentos amorosos. Paixão (vértice esquerdo do triângulo). A paixão é o elemento que se refere às movimentações que conduzem ao romance, à atração física, à relação sexual e aos fenômenos relacionados ao amor propriamente dito. Compromisso (vértice direito do triângulo). Trata-se, num aspecto mais restrito, de uma decisão por amar o outro, e num aspecto mais abrangente, o compromisso desse alguém para manter este amor. (GOUVEIA et al., 2009, p. 32).

O triângulo amoroso revela "uma metáfora, sendo que cada componente apresenta diversos aspectos do amor." (MORAIS, 2005, p. 35). Cada vértice do triângulo proposto por Sternberg pode ser visto separadamente; mas também interagem entre si, resultando em um tipo específico de relação amorosa, ou seja, em uma modalidade diferente de amor. Baseandose nesse triângulo, Sternberg propõe sete tipos de amor, de relação amorosa: gostar, paixão, amor vazio, amor romântico, amor companheiro, amor inconsequente, amor consumado. (SILVA et al. 2013).

A presença dos três componentes estabelece o amor pleno, enquanto que a junção de dois deles indica outras formas de amar. A combinação entre intimidade e paixão, chamado de amor romântico, significa que mesmo próximos e desejando estar junto, o casal não 
tem a certeza de que isso será possível. Intimidade e decisão/compromisso (companheirismo) fazem com que os parceiros permaneçam unidos mesmo após o término do desejo sexual. Por fim, a paixão com decisão/ compromisso (amor factual) é como o amor à primeira vista no qual existe a atração física e a vontade de permanecer juntos, mas o casal ainda não desenvolveu intimidade. (MÔNEGO e TEODORO, 2011, p. 97-98).

Sternberg salienta que cada indivíduo possui seu próprio triângulo amoroso, que se modifica com o tempo, de acordo com as mudanças que ocorrem no indivíduo; e cada um de seus vértices deve estar sempre em equilíbrio para que a relação à qual se refere se mantenha. Mas para que os triângulos dos indivíduos estejam em sintonia é preciso que sejam semelhantes; sendo que as diferenças entre os triângulos das pessoas envolvidas no relacionamento podem ser corrigidas e aperfeiçoadas através de uma proposta terapêutica. (MÔNEGO e TEODORO, 2011)

No entanto, a simples presença dos três componentes no triângulo amoroso não garante o sucesso da vida conjugal. Para Mônego e Teodoro (2011), o sucesso de um relacionamento depende de outras características isoladas que constituem a identidade sociohistórica e cultural daquele indivíduo; são essas mesmas características que irão guiar a busca pelo amor que cada um considera ideal para si. Por exemplo:

[...] características sociodemográficas como escolaridade, número de filhos, nível socioeconômico e cultural e crença religiosa. Outros estão associados às experiências românticas anteriores ou ainda a constructos como proximidade, intimidade, coesão, estabilidade conjugal e estilos de amor. (MÔNEGO e TEODORO, 2011, p. 98).

Ao analisarmos as duas teorias observamos que os conceitos podem ser vistos como relacionados. $\mathrm{O}$ padrão de apego seguro (TA) se assemelha à noção de intimidade e paixão da (TTA), que resulta no amor romântico. O padrão de apego ansioso (TA), se relaciona com a noção de intimidade e decisão/compromisso (TTA), onde existe a presença de ciúmes, mas mesmo assim, diante de altos e baixos, o casal permanece junto fortalecendo os laços que os unem, sendo um deles o companheirismo. E o padrão de apego evitativo (TA) se relaciona a noção de decisão/compromisso (TTA), pois em ambos os conceitos têm presente a dificuldade de a intimidade do casal se desenvolver.

Também percebemos que esses conceitos centrais estão carregados de possibilidades de mudança, no âmbito das duas teorias, o que significa que nenhum deles é um resultado definitivo, podendo sempre ter seu curso alterado dependendo do desenvolvimento da relação. $\mathrm{O}$ que quer dizer, por exemplo, que um relacionamento que é marcado pelo apego evitativo pode mudar, caso os indivíduos envolvidos alterem alguma atitude que fortalece esse tipo de comportamento, tornando o relacionamento marcado por um outro tipo de apego ou por uma outra modalidade de amor decorrente do encontro dos vértices de seus triângulos amorosos.

É possível, além disso, depreender que as duas teorias psicológicas sobre o amor recaem sobre o conceito contemporâneo de conjugalidade, sobre o quanto as escolhas amorosas das pessoas, baseadas em suas vivências e personalidades, podem afetar a forma com que conduzem o relacionamento amoroso.

A dificuldade de ser casal, reside no fato de o casal encerrar, ao mesmo tempo, na sua dinâmica, duas individualidades e uma conjugalidade, ou seja, de o casal conter dois sujeitos, dois desejos, duas inserções no mundo, duas percepções do mundo, duas histórias de vida, dois projetos de vida, duas identidades individuais que, na relação amorosa, convivem com uma conjugalidade, um desejo conjunto, uma história de vida conjugal, um projeto de vida de casal, uma identidade conjugal. (FÉRES-CARNEIRO, 1998, p. 380)

Ao pensar as teorias de Bowlby e de Sternberg, e tendo em vista a complexidade de um relacionamento amoroso, fica corroborada a afirmação de FéresCarneiro, dado que relacionar-se e compreender o amor é algo que requer um conhecimento mais profundo de si mesmo, partindo, além disso, do pressuposto de que o indivíduo guiará sua busca pelo amor a partir daquilo com o que se identifica.

O fracasso dos relacionamentos, que tende muitas vezes a ser justificado por algum deslize, acontece porque, na verdade, alguém se decepcionou com aquilo que buscou, com o que entendeu como sendo o seu ideal amoroso, como argumenta Féres-Carneiro (1998, p. 385) sobre o casamento: "os indivíduos se divorciam não porque o casamento não é importante, mas porque sua importância é tão grande que os cônjuges não aceitam que ele não corresponda às suas expectativas".

A busca pela experiência amorosa é algo subjetivo e mutável, pois o que em uma determinada fase da vida era visto como o amor ideal, hoje pode não fazer mais sentido, o que pode nutrir a vontade de procurar um relacionamento novo que seja completo e feliz, de acordo com as novas escolhas e as novas expectativas pessoais. Féres-Carneiro (1998, p. 382) ressalta que "a relação conjugal vai se manter enquanto for prazerosa e "útil" para os cônjuges". E nesse momento da contemporaneidade não há mais a pretensão de se viver o "felizes para sempre" - busca-se muito mais um relacionamento em que a satisfação pessoal, embora possa ser momentânea, seja o ponto principal.

\section{Considerações finais}

As diferentes concepções de amor no Ocidente, desde a noção apresentada por Platão até as formas como o amor é entendido na contemporaneidade, nos 
mostra o quanto essas concepções mudaram no decorrer do tempo e o quanto são subjetivas e pessoais. Ao procurar responder à indagação do porquê buscamos um relacionamento amoroso, nos deparamos com o fato de que manter uma relação de amor se vincula a necessidades individuais, dependentes das escolhas que decorrem do momento social, histórico e cultural em que os indivíduos estão inseridos, assim como com as suas visões de mundo.

A fragilidade dos laços humanos vivenciados na contemporaneidade transformou o amor em mais uma mercadoria, que pode ser consumida e trocada por outra melhor e mais nova quando deixa de produzir satisfação. E um relacionamento adulto pode envolver a perda da individualidade, pela entrega total ao outro, e a perda da privacidade, principalmente, no uso dos recursos do mundo virtual. No entanto, é possível a construção de um relacionamento de amor bem-sucedido, dia após dia, consolidado pelo enfrentamento dos conflitos, pelas oportunidades de os indivíduos irem se reconhecendo dentro da relação e por passarem a enxergar o outro real, sem o recurso da fantasia.

$\mathrm{E}$ as teorias psicológicas sobre o amor ampliam nossa compreensão a respeito dos fatores que podem influenciar os relacionamentos conjugais, tais como a concepção que o indivíduo tem de si mesmo e como isso afeta os aspectos que nutrem a conjugalidade. Falando sobre o amor, percebemos que esse amplo campo sentimental mostra várias faces, que se apresentam de formas distintas para cada indivíduo envolvido em um relacionamento amoroso. Portanto, o relacionamento de amor não deve se basear em padrões, pois a experiência do amor é única para cada ser humano, não podendo ser comparada com a de nenhum outro.

\section{Referências}

BAUMAN, Z. Amor Líquido - Sobre a fragilidade dos laços humanos. Rio de Janeiro: Zahar, 2004

BRAGA, P. O processo da hipermodernidade. Dissertação de Mestrado. Repositório Institucional PUCRS, 2010

DALBEM, J. X.; DELL'AGLIO, D. D. Teoria do apego: bases conceituais e desenvolvimento dos modelos internos de funcionamento. Arquivos Brasileiros de Psicologia, v.57, n.1, p.12-24, 2005.

FÉRES-CARNEIRO, T. Casamento contemporâneo: o difícil convívio da individualidade com a conjugalidade. Psicologia: Reflexão e Crítica, v.11, n.2, p.379-394, 1998 .

GOUVEIA, V. V.; FONSECA, P. N.; CAVALCANTI, J. P. N.; DINIZ, P. K. C.; DÓRIA, L. C. Versão abreviada da Escala Triangular do Amor: evidências de validade fatorial e consistência interna. Estudos de Psicologia, v.14, n.1, p.31-39, 2009

KUHN, N. L. Eu, tu, nós, e a busca do "eu" nos relacionamentos amorosos. Psicologia PT. O portal dos psicólogos. p.1-6, abr. 2013.

MAHEIRIE, K.; PRETTO, Z.; TONELI, M. J. F. Um olhar sobre o amor no ocidente. Psicologia em Estudo, Maringá, v. 14, n. 2, p. 395-403, abr./ jun. 2009.

MÔNEGO, B. G.; TEODORO, M. L. M. A teoria triangular do amor de
Sternberg e o modelo dos cinco grandes fatores. Psico USF, v.16, n.1, p.97$105,2011$.

MORAIS, L. A natureza do amor romântico. Tese de doutorado. Universidade Lusófona de Humanidades e Tecnologias. 2005.

ROGRIGUES, S.; CHALHUB, A. Um amor com dependência: um olhar sobre a teoria do apego. Psicologia.pt - O Portal dos Psicólogos. Monografia, p.1-15, 2009.

SAVIAN FILHO, J. Filosofia e filosofias - Existência e sentidos. Belo Horizonte: Grupo Autêntica, 2016.

SHIRAMIZU, V. K. M.; LOPES, F. A. A perspectiva evolucionista sobre relações românticas. Psicologia, USP, v.24, n.1, p.55-76, 2013.

SILVA, P. O. M.; TRINDADE, Z.; SILVA JUNIOR, A. Teorias Sobre o Amor no Campo da Psicologia Social. Psicologia: Ciência e Profissão, v.33, n.1, p.16-31, 2013. 